\title{
Health Advisory Service
}

We are publishing part of Dr Horrock's final report of the Health Advisory Service, June 1987. The President wrote to him asking to amplify his statement that "Participation and leadership in the process of change needs to be regained by the respective professional bodies, not least by The Royal College of Psychiatrists". His reply to the President follows his report.

\section{Progress in mental health services}

As mentioned in the introduction to this report, mental health service provision is currently a matter of major concern and debate in almost every District visited by HAS. Gradual evolution of new forms of treatment and changing public perceptions of mental illness have been overtaken by a series of structural alterations which are not professionally led in terms of pace or sometimes even direction. For psychiatrists, the requirements of the new Mental Health Act and the growing independence of allied professional colleagues have been further external influences to which adjustment has been necessary. Many consultant psychiatrists have told teams of the harm which they genuinely fear will befall their patients in the new forms of mental illness service that are emerging. Such anxieties should not be ignored.

What is not at issue is that change is necessary. There is very broad agreement that large mental hospitals do not offer environments that facilitate sensitive individual treatment of mentally ill people and that their use has hindered the recovery of many. It is also common ground that future patterns of treatment should be non-stigmatising, provided close to home if not in the home and should ensure the integration of all the necessary skills, including those of the primary care teams and social services departments. Already HAS teams have reported countless examples of service provision which show the potential for patients and staff of these new approaches. It may be helpful to analyse some aspects of change which have emerged as particularly difficult in the course of our visits.

In recasting services, planners place great reliance on nationally or regionally applied standards of provision of staff, beds and other resources. In fact, psychiatric morbidity variations are massive and strongly related to social deprivation and instability. Thus the level of service required in a prosperous locality will be entirely inadequate when offered in an inner city community. Yet very often such differences are ignored, leading to a loss of credibility of the plans. Realistic planning must be based on knowledge of local morbidity patterns and the necessary data must be obtained.

Overshadowing every District's efforts to revise mental health services is the question of resources. In most Regions there are theoretical mechanisms by which savings made as reliance on the large hospitals is reduced can be recycled to support the new services. Not all Regions however have made arrangements to cover the costs of providing the new services in advance of savings being realised - the 'pumppriming' or 'bridging' costs-and some say they are unable to do so. The result is a variety of ad hoc allocations which do not create confidence that the needs of patients will be met in the interim.

Further, there is every justification for savings being achieved in the large hospitals to be at least partly devoted to improvement of the more unsatisfactory environmental conditions and staffing levels in those hospitals. Although a minority will close very soon, most have a life expectancy of several years at least. Too often it seems that new services are being achieved at the expense of good quality care for the many patients who are still part of the old system.

General financial pressure on health authorities continues to result in instances where savings achieved in mental health services are siphoned off to rectify budget deficits resulting from overspending in, for instance, acute medical or surgical services. Even if mental health service funding were adequate such manoeuvres would be questionable; instead there is every reason to believe that redeveloped better quality services will demand increased funding. The original hypothesis that simply redeploying existing expenditure would suffice is becoming untenable, though there are undoubtedly opportunities for using existing resources better.

Modern mental illness services will require higher levels of staffing by consultants, nurses, psychologists, therapists and social workers than existing models because of the dispersed nature of the new provision and the greater emphasis on individual assessment, treatment and rehabilitation rather than containment and 'care', often largely by untrained staff. Aside from the greater expense implied, the availability of greater numbers of such qualified staff is proving to be a major limitation on implementing new services. In particular, some health authorities are finding that they cannot open new facilities because it is impossible to recruit nurses who are qualified in mental illness nursing. At a time when the need for such nurses is escalating, the numbers in training are lower than ever owing to the withdrawal of pupil nurse training.

Opportunities for existing mental health workers to retrain to contribute to community-based services are also insufficient. Too many are unsure of their roles in the revised services and have had little in the way of counselling or support. Such uncertainties are found even amongst 
senior professional staff. Very often plans are made without the involvement of those whose job it will be to implement them. Such lack of 'ownership' contributes greatly to the present unease.

Dispersed services inevitably imply a greater degree of shared responsibility for patients amongst different professional groups and between agencies. For psychiatrists, used to the concept of overall clinical responsibility, there are particularly difficult adjustments to be made. Not all accept that other professions can take direct responsibility for patients at all. Most are willing to share decisionmaking with colleagues from other professions and are reaching understandings on the specific contributions which each can make. Confidentiality is a further issue in these circumstances, not least in child and adolescent psychiatry where the number of agencies involved is often large. Interprofessional and interagency collaboration and trust need time and patience to develop. The time scale in many Districts for remodelling mental illness services is proving too rapid for such essential relationships to emerge.

A very large proportion of mentally ill people are treated by family doctors without recourse to specialist psychiatric services. There are now many individual examples of effective links being created with primary care services by community psychiatric nurses and clinical psychologists and these are very much welcomed by general practitioners. About one fifth of consultant psychiatrists spend some time in primary care settings. It is therefore disappointing that most plans for new community-based mental health services make little acknowledgement of the need for an integrated single service. Instead the common pattern is to provide outposts of the specialist services which will exist separate from and parallel to those provided by family doctors. Representative general practitioners and Family Practitioner Committees rarely figure in mental health service planning.

A worrying misconception encountered by many teams has been the belief that acute psychiatric unit provision in or near a general hospital will wholly replace the functions of a large mental hospital. Some plans have been little more than the replacement of one large hospital by a number of smaller versions of the same facility. District general hospital units have been proved to enhance psychiatric liaison with other specialities and have ensured the treatment of much hitherto unsuspected serious mental illness. They reduce stigma and improve access for patients and their families. Such units do not however provide satisfactory accommodation for patients with more than temporary behavioural disturbance or for those with chronic mental illness. Rehabilitation is probably more difficult to achieve in the confines of a general hospital. And where standard hospital wards have been allocated to psychiatry in general hospitals they are far too limiting in terms of space.

The large mental hospitals provided for a wide variety of patients and accommodated many of the special psychiatric services as they evolved. The move to more locally-based patterns of provision is posing problems for such services. Many depend for their viability on a catchment population much larger than a single District. Individual consultant psychiatrists are finding conflict between their specialism and their new responsibilities to a smaller defined population.

The large hospitals were also able to absorb small numbers of patients with atypical mental disorders of organic origin. The contraction of the large hospitals is revealing the need for special provision to be made for such patients, notably those with mental disorder following head injury and sufferers from Huntington's chorea.

Many plans are found to be weakest in respect of patients with chronic mental disorder, yet it is clear that the way in which such patients and their families are to be supported in the new forms of mental illness service will be the real test of their success. For existing long-stay patients there are still many examples of arbitrary resettlement based on inadequate or superficial assessment of their needs and insufficient rehabilitation. However successful the more sensitive locally-based services prove to be, there is general acceptance now that there will continue to be numbers, albeit smaller, of patients with high levels of dependency for whom continuing close professional attention will be required. Amongst those plans where the needs of such people are actually acknowledged there is no consensus about the style of provision required.

Previous reports have covered the difficulties surrounding joint planning between health and local authorities and these continue. It is encouraging that jointly agreed mental health strategies are now beginning to emerge in a few more Districts but progress is still slow. Many local authorities now report that they cannot match the pace of planning being set by the health authorities and their general managers. Much distrust and disagreement persist about the resources needed to implement new services, about the degree of dependence which can be placed on the voluntary sector and about the geographical sectorisation of services to individual communities.

As revised forms of mental health service emerge, there is a need for evaluation of their effects. The requirement to relate provision more closely to need has already been mentioned. As part of joint planning, a few authorities have agreed to compile registers of people at risk. Credibility will depend everywhere on the acceptance of joint responsibility for patients and families needing continuing support. The complete withdrawal of responsibility by health authorities seen in previous large scale reductions of mental hospital populations must not recur. The costs of providing such evaluative information must be included in budgets for new service development.

The various difficulties outlined as currently affecting mental health service development would be individually worrying. Taken together I believe that there is cause for serious concern. The momentum for change in mental illness services is welcome and should not be put into reverse. Nevertheless action is called for on the part of government and by regional health authorities. Participation and 
leadership in the process of change needs to be regained by the respective professional bodies, not least by the Royal College of Psychiatrists.

The pressure by central government for closure of large mental hospitals exercised through ministerial and managerial review processes must now be accompanied by more realism about the financial resources, staff and planning arrangements involved. The review of community care already being undertaken by Sir Roy Griffiths will cover the way in which public funds are being used to support community care policies and will be looking at ways of improving interauthority arrangements. The Griffiths review can therefore be expected to influence government policy significantly in the future care of mentally ill people.

Additionally, though, it will be helpful for government to acknowledge that overall mental health expenditure may well need to be greater than at present if adequate services are to emerge. Central provision of 'bridging' finance ought to be introduced to underwrite the costs of double running in the process of change. There should be specific government protection of existing mental health expenditure.

Urgent national action should be taken to ensure the necessary recruitment and appropriate training of psychiatric nurses, based partly on reassessment of the skill mix required. Means should be found to overcome the professional and employment barriers which are obstructing the retraining of health workers to take part in community care services. Further national attention should be directed to the issue of confidentiality between agencies caring for mentally ill adults and children.

In monitoring the plans of individual health authorities, regional health authorities should ensure that the environments and staffing of the large mental hospitals are not neglected during the process of change. Plans should include specific commitments to the local measurement of need and to continuing evaluation of effectiveness, particularly in respect of continuity of care for those with chronic mental illness. They should encompass arrangements for staff counselling, retraining and redisposition.

Integration of future mental health services with primary care should be made explicit in District plans; they should include the whole spectrum of services to be created, going well beyond the simple re-siting of hospital beds.

Guidance from professional bodies like the Royal College of Psychiatrists is badly needed on standards of service on which plans can be based and evaluation exercised. The process should not involve setting precise national norms for beds or staff but should provide statements on the necessary components of District psychiatric services. Particular guidance is needed on the content of community psychiatry, on collaboration with primary care, on methods of evaluation and monitoring, on the place of specialist psychiatric services in the context of locally presented generic services and on rehabilitation. The service needs of patients with chronic mental illness and those with organic brain damage are particularly pressing.

In evaluating training programmes, the responsible professional bodies should lay much greater emphasis on interdisciplinary and inter-agency collaboration and monitoring and self-evaluation as essential components of the training experience.

Above all, professional organisations cannot be the passive recipients of managerially driven change. They must participate with and guide the development of better care and treatment for mentally ill people, ensuring that the necessary changes are made in ways and at the pace which will protect and enhance the lives of the very vulnerable people concerned.

\section{Mentally handicapped people}

The Health Advisory Service relinquished responsibility for the over-sight of services for mentally handicapped people in England eleven years ago. A responsibility for such services in Wales has continued but a review has been requested recently as to whether this is still appropriate. Nevertheless, in the course of recent visits the needs of mentally handicapped people now living in community settings have come to the attention of teams. There seem to be two issues which may become important and are worth highlighting.

The first is the position of elderly mentally handicapped people. Disagreements about their management in the event of illness requiring hospital treatment have been noted. Teams have taken the line that patients should have full access to specialist geriatric medical services in such circumstances. It is widely accepted that they should be offered the full range of domiciliary health and social services according to need as well as continued access to services for mentally handicapped people.

Secondly, our visits have revealed unease in some Districts about the management of mentally handicapped people with mental illness and/or behavioural disturbance. With decreasing emphasis on the hospital element of care, traditional institutional management within the mental handicap service may be a less available option but openings into general psychiatry are also often not available for such patients. Effective working links between mental illness and mental handicap services are often not well established. Generally, the problem has increased and local policies need to be defined. 
Dear Dr Birley

Thank you for your letter of November 18 and for the generous and constructive tone of your comments on my final annual report from the Health Advisory Service. I particularly welcomed the news that there could be progress on the designation of the psychiatry of old age as a recognised specialism.

During my four-year spell at HAS and now in assisting progress in mental health services in Yorkshire, I have been tremendously encouraged to meet many consultant psychiatrists who are committed to change, to the creation of better services and to active participation in the planning and management of psychiatric services. Most, but by no means all, are young. They undoubtedly represent the future of psychiatry. I believe that their enthusiasm and foresight need the active support of the Royal College of Psychiatrists.

What follows is a putative shopping list of service-related issues on which College leadership is badly needed. If adopted, its contents could be the basis upon which psychiatrists regain influence and control in a rapidly evolving scenario. Much of what is happening, through ministerial, managerial and simple financial pressures, is misguided, short-sighted and inept. I am sure that, without putting developments into reverse, the College could be profoundly influential in ensuring a fare more effective and caring result.

\section{Research}

"... there are no British cost-effectiveness studies of alternative forms of community care for people with chronic mental illness" K. G. Wright: Cost-Effectiveness in Community Care, September 1987. University of York Centre for Health Economics.

In the absence of significant research findings, the commonest objection to progress in community care, that it is a step in the dark putting vulnerable people at significant risk, cannot be rebutted. Is the College able to influence the Department to undertake such research? Might it not itself undertake a study of the costs and benefits of community care?

\section{The components of a comprehensive service}

There is much ignorance amongst planners about the breadth of a comprehensive psychiatric service. A statement by the College detailing the necessary functions which must be supplied in every health district would be enormously valuable. It would encompass the general and specialist functions which ought to be provided by every District and those specialist services which will usually be shared by two or more.

The statement might be constructed along the lines of Donald Dick's chapter (4) in Common Concern, (MIND 1983). It would describe functions rather than norms, emphasise outreach to the operational spheres of other concerned agencies like general practitioners, local authority and voluntary services and specify consultant roles and responsibilities in each relevant function.
Particularly in need of emphasis is the variety of services required to identify, rehabilitate and give sustained support to those with chronic mental illness. What are the roles of the hospital in this process? Should every District have an at-risk register or index shared with other agencies to ensure systematic cover to known sufferers? The potential list is endless but key statements on continuity of responsibility and comprehensiveness seem essential.

Work by Professor Hirsch's group on acute bed norms for psychiatry seemed to conclude that local variations in demand (determined by history, staffing, social and economic conditions, housing and so on) make national norms inappropriate. The need is clearly to develop mechanisms by which the quantity of service required is judged according to local needs. Is the College not in a unique position to advise on how this might be done? Some such system of community assessment is a vital component of each District's psychiatric services and could be specified as such.

Emanating from the Royal College of Psychiatrists, a statement of this nature would have a powerful and immediate influence on planning, strengthening the position of psychiatrists being asked to provide services with only a fraction of the necessary components.

\section{Evaluation and standards}

The College should endeavour to generate a climate in which continuous evaluation of psychiatric services is the norm. To quote Professor Crisp and his colleagues (Medical Education, 1984, 18, 110-116):

"Without serious evaluation of the services we provide, we will never be able to be confident that what we are doing is the best we can offer."

Requiring evidence that the commitment and resources for internal audit exist should become part of the approval process for general and higher psychiatric training

The College should accept responsibility for providing external standards by which clinical activity can be subject to audit. As a tentative example, might the College's valuable statement on the desirable facilities for electroconvulsive treatment now be augmented by professional guidance on the use of ECT, by which individual psychiatric services might judge themselves? Such guidance and protocols of management developed by the College on a variety of subjects would do much to enhance the status of psychiatry in my view. The very wide variations in practice now current do not assist credibility.

Self-audit will inevitably become a managerial requirement on clinicians. It will be wise for the College to be ahead of the process rather than responding defensively at a later stage.

\section{Interprofessional collaboration}

The transition to more dispersed forms of delivery of psychiatric care and treatment inevitably implies a greater degree of sharing and delegation of responsibility to other professions, notably nursing, social work and clinical psychology, and to general practitioners. For many 
psychiatrists, loss of direct control of some resources and reliance on the training and opinions of non-medical colleagues are hard to adopt.

The College could perhaps develop greater awareness of the importance and benefits of interdisciplinary collaboration amongst its members. One route might once more be through training approval. Is the presence of modern interdisciplinary practice a requirement for a department to be approved? Should it not now be mandatory?

A second approach might be for the College to review its 1977 statement 'The Responsibilities of Consultants in Psychiatry within the NHS'. Professor Rawnsley's 'Future of the Consultant' report acknowledged the potential problems posed by 'community psychiatry' and recommended continued 'surveillance'. Definitive statements about the dynamics and methodology of interdisciplinary collaboration from the College would be very helpful. I was very impressed by Professor Goldberg's analysis of professional and clinical responsibility presented at the joint meeting which the College held with the British Psychological Society.

The ways in which psychiatrists can relate to general practitioners are numerous. They include collaboration in planning; joint responsibility for some patients; and the numerous forms of outreach work with family doctors. A lead statement on desirable practice from the College, perhaps best developed with the RCGP, would be valuable.

\section{Service management and joint planning}

The initiatives taken by the Royal College of Psychiatrists to encourage senior registrars and recently appointed consultants to have training in management are very welcome. I believe requirements on this are now part of the evaluation of some higher training programmes in psychiatry-is it universal?

I have been struck by the lack of appreciation of the mechanisms, constraints and potential of inter-agency planning shown by many psychiatrists. For many, the process is unfamiliar and the business of 'others', although the resulting decisions directly affect the style and content of psychiatric practice. Frustration and anger result. There is a clear need for psychiatrists to be involved in interagency planning, at all stages and levels. The College could be very specific about this. It might accept the onus of stimulating training and seminars on service planning for psychiatrists.

\section{Other issues}

Successive annual reports from the Health Advisory Service have highlighted examples of generalised failure of effective services provided for specific groups. An early example was the disorganisation of arrangements for adolescents with disturbance and the College's subsequent interest is doing much to put matters right, albeit gradually. More recently HAS has drawn attention to:

conditions in long stay wards for elderly people arrangements for mentally handicapped people with mental illness

arrangements for younger people in whom head injury and other organic diseases cause behavioural problems

I believe that the College could usefully advance provision for such neglected groups by publishing its own concerns and recommendations widely and forcefully.

I have attempted to respond to your request as positively as possible, giving almost the whole emphasis to what I perceive as needs for the immediate future and disregarding the current invaluable achievements of the College in so many other areas. My own contacts with the College, in particular with the sections on old age psychiatry and social and community psychiatry, leave me in no doubt that it has a wealth of well-motivated and committed people capable of picking up the challenges I have offered. The timetable for action should be short in view of the rapidly changing scene. I am convinced that the Royal College of Psychiatrists can be instrumental in ensuring that the very different psychiatric services of the next century are given the best possible foundations today.

Yorkshire Regional Health Authority

Peter Horrocks 